\title{
Diagnostic Laboratories - Are These Radiation Safe?
}

\section{R.RAJAN* AND PAUL RAJAN RAJKUMAR}

Doctoral Research Scholar, Saveetha School of Management, Saveetha University, Chennai, Tamil Nadu, India

Professor, School of Management Studies, Bannariamman Institute of Technology, Sathyamangalam, Tamil Nadu, India.

\section{Email: rajan_1704@rediffmail.com}

Received: December 14, 2016 l Revised: February 09, 2017| Accepted: March 11, 2017

Published online: April 10, 2017

The Author(s) 2017. This article is published with open access at www .chitkara.edu. in/Publications

\begin{abstract}
The demand for Diagnostic Centers in India is propelled by changes in culture, increase in population, rise in infectious disease, increase in healthcare expenditure and rising adoption of preventive health check-ups. The Private diagnostic market in India has limited number of organized players and the overall market is driven by unorganized laboratories. The Diagnostic Imaging equipments such as X-ray, CT (Computed Tomography) Scanner and BMD (Bone Mineral Densitometer) need to be handled with utmost care as they have human made ionizing radiation exposure risks. India is one of the largest consumers of refurbished diagnostic imaging equipments and the beneficiaries include Diagnostic Centers, Corporate Hospitals and Chain of Diagnostic Laboratories. The Atomic Energy Regulatory Body (AERB) in India regulates the usage of diagnostic imaging equipments by evolving policies and procedures to be strictly followed by Diagnostic Centers for containing excessive radiation. The changes in procurement policy made by AERB in September 2015 have restricted importing of used diagnostic imaging equipments up to a maximum of 7 years. This regulatory change has triggered a research question, Diagnostic Laboratories - Are these Radiation Safe? This research was conducted with the objective of assessing whether diagnostic centers follow the best practices mandated by AERB. The researcher has conducted a very structured assessment on AERB compliance using 7 different parameters namely, Regulatory, Layout Engineering, Technician Competency, Human Safety, Operations Knowhow, Radiation Exposure Monitoring and Top Management Commitment. This study was conducted in 192 diagnostic centers across multiple cities in
\end{abstract}

\footnotetext{
Journal of Multidisciplinary Research in Healthcare Vol-3, No-2, April 2017 pp. 99-123
} 
Rajan, R

Rajkumar, PR

Tamil Nadu, with a structured questionnaire contained 34 questions. Based on the responses received on the actual practices followed by diagnostic centers to contain Radiation risk, Radiological Compliance Index (RCI) was estimated. The analysis has revealed that Top Management Commitment was very low with a RCI score of 2.02 (Moderate Presence of AERB recommended best practices) and Operations "Know-Know" was high with a score of 4.40 (High Presence of AERB recommended best practices). The comparative analysis of RCI between National Accreditation Board for testing and Laboratories (NABL) accredited (RCI Score 3.19) and Non NABL (RCI Score 3.18) diagnostic centers has indicated that the accreditation did not significantly influence the compliance. The Pearson correlation co-efficient has established moderately positive correlation with Revenue (+ 0.321) \& Patient Queue size (+0.293) on RCI. This study has concluded with sufficient evidence and analysis that Private Diagnostic Centers need to focus on appointing Radiation Safety Officer, monitoring radiation exposure dosage, periodical equipment service, continuous training of their staff and periodical QA tests for equipment fitness in order to achieve significant regulatory compliance maturity levels. This research has further recommended similar research in private diagnostic laboratories in other states in India and comparative analysis of compliance to AERB guide lines between Government Hospitals and Private Diagnostic Centers.

Keywords: Diagnostic Imaging Equipments, Atomic Energy Regulatory Body (AERB), Total Quality Management (TQM), Radiation Control Measures, Top Management Commitment, Radiation Compliance Index

\section{INTRODUCTION}

The healthcare market in India is expected to grow from 6,70,000 Crores (INR) in 2015 to $18,76,000$ Crores (INR) in 2022 (Shown in Fig1. Market

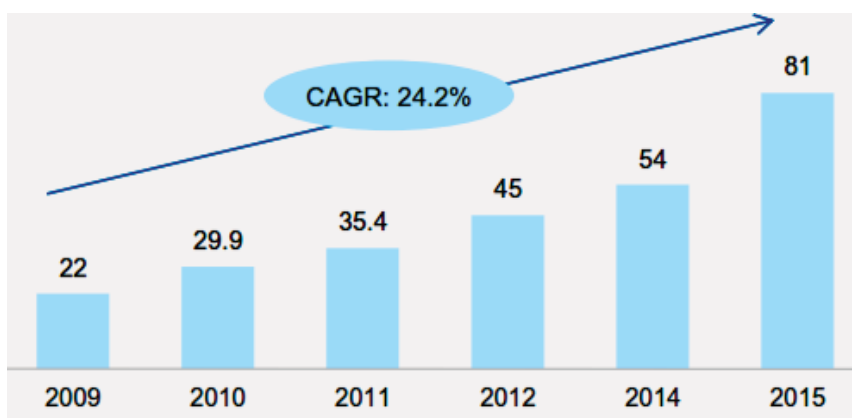

Figure 1: Market Size of Private Hospitals (USD billion). 
Size of Private Hospitals). The healthcare expenditure is forecasted to expand at a CAGR (Compound Annual Growth Rate) of 17 percent over 2011 to 2020. The traditional health problem is replaced by lifestyle related disease and 50 percent of spend is on in-patient beds. There is a substantial demand for specialized high quality healthcare in Tier II and Tier III cities.

The diagnostic market is set to grow at a CAGR of 20.4 percent to USD 32 billion from USD 5 billion over 2012-2022 (shown in Fig 2. Market Size of Diagnostic Market). The diagnostic market is split between imaging and pathology with thirty percent and seventy percent share respectively.

The doctor-to-patient ratio for rural India, as per Health Ministry statistics stands at 1:30,000, which is well below World Health Organization recommendation (WHO) of 1:1000 (Source: WHO, IMH, Deloitte, EBH, Tech SCI Research, Jan 2016). This establishes very high potential for Diagnostic Centers to grow across smaller towns in India.

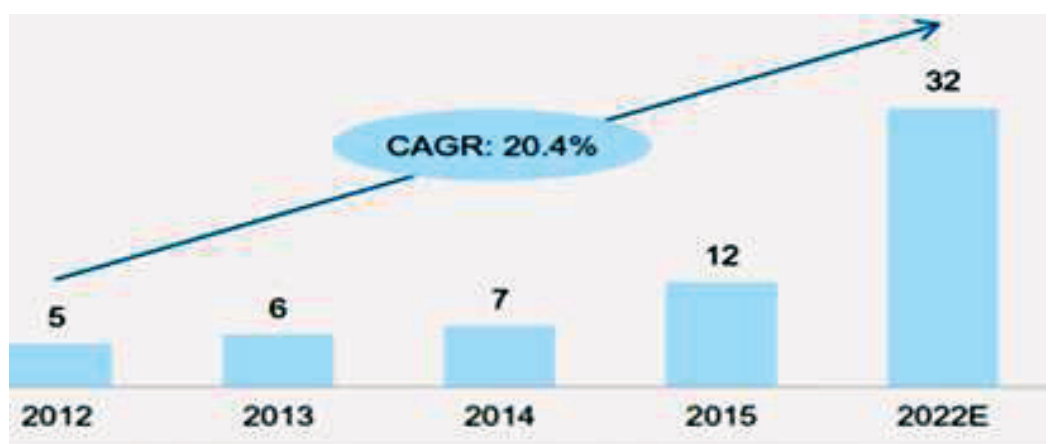

Figure 2: Market Size of Diagnostic Market (USD billion).

\section{LITERATURE SURVEY}

The use of radiation for medical diagnostic examination contributes over 95 percent of human made radiation exposure. In fact for several developed countries, the increased use of high dose x-ray technology in particular Computed Tomography (CT) has resulted in a situation in which the annual collective and radiation doses of ionizing radiation due to diagnostic radiology have exceeded those from natural background radiation. In light of this marked increase in worldwide collective effective dose from medical diagnostic procedure and with CT scans accounts for half of this, there is great emphasis on the subject of radiation protection of patients in CT. The American Food and Drug Administration jointly with Conference of Radiation Control Program Directors released a report titled "What Next" in 2000 which has claimed 46
Diagnostic Laboratories - Are These Radiation Safe? 
Rajan, R

Rajkumar, PR million CT procedures were performed in a year with a standard error of 4 million. Mettler et al., (2000) has studied patterns of CT use and dose levels. They have revealed that the percentage of CT scans has been doubled over a ten years period in USA, based on the review of reports in their institution. The cost effectiveness of whole body CT screening has been extensively studied by Beinfeld et al., (2005). The estimated radiation risks potentially associated with full body CT screening was comprehensively studied by Brenner \& Elliston (2004). A study on the effect of radiation when performing mass screening using CT colonography was conducted by Brenner \& Georgsson (2005). The risk of cancer from diagnostic x-rays based on the study performed in 14 different countries has been published by Berrington de Gonzalez \& Darby (2004).The organ doses corresponding to a common CT study, 30 to 90 millisievert dose can increase the risk of cancer. The cancer risks attributable to low doses of ionizing radiation have been clinically studied by Brenner, Doll \& Goodhead (2003). The health risks from exposure to low levels of Ionizing radiation have been further studied in detail by Richard Monson et al., (2006). The effect of unjustified CT examinations in young patients has been studied by Oikarinen et al. (2009). Too many CT scans recommendations due to the advent of technology and the rapid speed in which the diagnosis results response rates are expected are the main causes for this increasing radiation exposure. The development of new concepts in CT and its implication on the obsolete technology has been studied by Brenner and Hall (2007). The risk associated with low dose CT screening of adult smokers for lung cancer and the need for reviewing the dose index has been narrated by Brenner $(2004 \&$ 2006). The study performed by Giles (2004) has highlighted the avoidable risks of CT scans.

Linton and Mettler (2003) have presented their view on dose reduction in CT with an emphasis on pediatric patients. The Radiation Protection Referral Guidelines for medical imaging availability and use, published by European Union was designed and published after collaborating with more than 40 countries Radiation experts. Djermouni \& Boal (2007), scientific officers worked in the International Atomic Energy Agency (IAEA) have compiled and released multiple standards and reports for application of best practices in dealing with Ionizing Radiation for the regulators. Ortiz Lopez (1999 \& 2006) has compiled various contributions by radiation experts across the globe in the form of reports covering radiation safety in nuclear medicine, Radiotherapy and safe guarding from the sources of ionizing radiation. Martin et al., (1999) has studied the need of balancing patient dose and image quality. In order to promote the awareness on CT radiation, McNitt-Gray (2002) has published a tutorial for residents on Radiation dose in CT. The workshop organized 
by European Union Radiation expert's team was participated by more than 40 country representatives in September 2012 in Vienna has discussed and exchanged radiation dose information, specific advice for imaging children, radiation exposure to pregnant woman and best practices to handle $\mathrm{x}$-ray equipments for its optimal and effective use. It was expressed that more than 70 percent of participating countries knew their country specific legal requirements and the respective guideline for containment of radiation exposure. However, the concern expressed by the representatives was that the adoption of such guidelines, periodical monitoring and continuous improvements are not in place.

\section{RESEARCH DESIGN}

\subsection{Research Question}

Based on the extensive literature survey, the researcher has concluded that there are adequate research work needs to be under taken in Healthcare domain towards radiation containment in Diagnostic Centers. Hence, the research question was designed to reflect this intent as, "Do Private Diagnostic Centers housing diagnostic imaging equipments follow the practices laid down by $A E R B$ on regular basis for radiation containment?"This study is confined only to Private diagnostic laboratories with in southern part of India.

\subsection{Research Objectives}

- To assess the maturity of business processes based on the best practices followed by the Private Diagnostic Centers, in line with AERB recommended regulatory guidelines for containment of handmade Ionizing Radiation through the usage of Computed Tomography and $\mathrm{X}$-ray machines

- To extensively study and analyze the key parameters such as Regulatory, layout Engineering, Technician Competency, Operational Know-How, Human Safety, Monitoring Radiation Exposure and Top Management Commitment, which constitutes the overall Radiological Compliance

- To compare the regulatory compliance between NABL accredited and Non-NABL Diagnostic Centers

- To assess the relationship between "Revenue and Regulatory Compliance" and "Patient Queue size and Regulatory Compliance"

\subsection{Research Hypothesis}

The presence of Private Diagnostic Centers for offering the initial diagnosis and reporting are plenty and the demand for such services are forecasted
Diagnostic

Laboratories - Are

These Radiation

Safe?

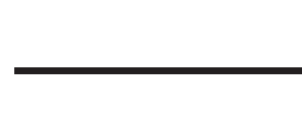


Rajan, R Rajkumar, PR to grow in light of the increased health awareness among people. The regulatory compliance and quality certifications would be used as a unique selling proposition for enhancing the image of the diagnostic centers there by increasing the revenue. Hence Diagnostic Centers which are certified for NABL accreditation are inclined to score high on the regulatory requirements than Non-NABL centers. The researcher has designed a hypothesis to assess whether NBAL accreditation influences the regulatory compliance score as below.

H1: NABL accredited Private Diagnostic Centers are inclined towards higher compliance with regulatory guidelines

The allocation of funds for operation budgets proposed by the leadership team in any organization depends largely on the revenue earned. The implementation of regulatory standards involves sizeable effort and fund for dissemination across the organization. This has motivated this study to formulate a hypothesis relating Revenue with Radiological Compliance Score.

H2: Diagnostic Center's Revenue has positive impact on the compliance score

\subsection{Sampling Procedure}

The universe has been defined using a detailed search with the help of "Google Search Engine", which has been conducted by the researcher through publicly available information sources. The search included List of registered X-Ray users, Registered Diagnostic Centers and AERB published X-Ray users respectively. The following open information sources on institutions using $\mathrm{X}$-Ray equipments were identified.

- List of National Accreditation Board for Testing and Laboratories (NABL) / National Accreditation Board for Hospitals and Healthcare Providers $(\mathrm{NABH})$ accredited Diagnostic Imaging Centers in India

- Online portal (www.healthfrog.com) on registered hospitals in India

- List of licensed Medical Diagnostic X-Ray facility in India, published by AERB with last update date as on 24th October 2016

From the above information sources and criterion, the universe has been defined. The Universe included institutions (diagnostic centers) having any one of Imaging Radiological Equipments (CT, X-Ray, BMD and Mammography). The researcher reviewed them on the basis of their license. The licensed medical Diagnostic X-Ray facility within Tamil Nadu is 352, which stands as a definite universe of this research study. The samples have been derived accordingly through a methodical process. Initially, a formal communication has been sent through email addressing to a majority of Radiologists and Technicians across 
all 352 institutions in Tamil Nadu was approached by explaining the objective of this research study and its intended benefits. Finally, 192 respondents who have agreed to participate in the research study were included as samples. List of institutions under each of strata, location (name of city) and call coordinates (email and contact information) were collected for this present research study. The stratified random sampling technique has been adopted to identify the samples randomly from each stratum.

\subsection{Data Collection Instruments}

The present research study collected the primary data through sample survey. Hence, only licensed Medical Diagnostic Equipment facility listed and published by AERB have been included. The literature review on various research studies exhibited the non-existence of a standard prior instrument for measuring the best practices based on AERB guidelines for Medical Diagnostic Imaging in India. Hence, the researcher developed an instrument as per the requirements of study with seven different parameters such as Regulatory, Layout Engineering, Technical Competency, Human Safety, Operations Know-How, Monitoring Radiation Exposure and Top Management Commitment. The list of verification points under each parameter have been devised for assessing the practices and continuous adoption of standards. A seven-point scale has been used in the questionnaire against every item and choice of seven-point scale has been quite consistent with the existing literature on TQM and ISO systems, established by Fenghueih (1998).

\begin{tabular}{ccccccc}
\hline $\mathbf{0}$ & $\mathbf{1}$ & $\mathbf{2}$ & $\mathbf{3}$ & $\mathbf{4}$ & $\mathbf{5}$ & $\mathbf{6}$ \\
\hline $\begin{array}{c}\text { No Practice } \\
\text { Exists }\end{array}$ & $\begin{array}{l}\text { Marginal } \\
\text { Presence }\end{array}$ & $\begin{array}{c}\text { Moderate } \\
\text { Presence }\end{array}$ & $\begin{array}{c}\text { Significant } \\
\text { Presence }\end{array}$ & $\begin{array}{c}\text { High } \\
\text { Presence }\end{array}$ & $\begin{array}{l}\text { Very High } \\
\text { Presence }\end{array}$ & $\begin{array}{c}\text { Complete } \\
\text { Presence }\end{array}$ \\
\hline
\end{tabular}

\subsection{Reliability of the Instrument}

The reliability refers to the extent to which an experiment, test or any measuring procedure yields the same results on repeated trials, was explained by Richard Levin \& Davis Rubin (2001). The most popular reliability estimate has been given by Cronbach's Alpha, introduced by Cronbach (1951).The value of alpha varies between " 0 " and "1". As a general rule, reliability should not be less than 0.80 and supported by the fact that at that (0.80) level correlations are attenuated very little by random measurement error. The reliability test has been conducted with SPSS (version 20.0) for examining the consistency of the measurement instrument used in this research. The test result has indicated "no exclusions" (Refer Table 1) and Cronbach's alpha value as 0.943 (Refer Table 2). The Cronbach's alpha
Diagnostic

Laboratories - Are

These Radiation

Safe?

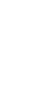

西


Rajan, R
Rajkumar, PR

Table 1: Scale Reliability Test Summary.

\begin{tabular}{ccc}
\hline \multicolumn{3}{c}{ Scale Reliability Test Summary } \\
\hline Summary & Total Size $(\mathbf{N})$ & Percentage \\
\hline Valid & 38 & 100 \\
Excluded & 0 & 0 \\
Total & 38 & 100 \\
\hline
\end{tabular}

Table 2: Cronbach's Alpha Test Results.

\begin{tabular}{cc}
\hline \multicolumn{2}{c}{ Cronbach's Alpha Estimation } \\
\hline Cronbach's Alpha & Number of Items \\
\hline 0.943 & 34 \\
\hline
\end{tabular}

value estimated for the measurement scale used in this research is 0.943 , which is well above the accepted limit of a minimum 0.80 . Hence, scales used in the measurement tool have been construed as reliable.

Furthermore, the researcher has also estimated Cronbach's alpha for every item included in the measuring instrument and identified that alpha value was above 0.9 for each item (table 3 ). This confirms that all 34 questions designed in the measurement tool can be included for this research study.

\subsection{Sample Sufficiency \& Sphericity Test}

The Kaiser-Meyer-Olkin (KMO) and Bartlett's test of sphericity is a measure of sampling adequacy, which is recommended to check the case to variable ratio for the analysis have been conducted. While KMO ranges from 0 to 1 , the world wide accepted index is 0.6 . Also, Bartlett's test of sphericity relates to the significance of study thereby exhibits the validity and suitability of the responses collected to the problem being addressed through this study. In order to conduct factor analysis, Bartlett's test of sphericity must be less than 0.005 .

The KMO and Bartlett's test results summary shown in table 4 indicated the $\mathrm{KMO}$ measure of sampling adequacy has been estimated as 0.718 , which is well within the acceptable limits. Hence, samples collected for this research study has been found acceptable for carrying out further analysis. Similarly, Bartlett's test of sphericity has shown "p" value as "zero", which signifies that responses collected using a structured instrument in this research study has been found appropriate and valid for analysis in line with the research objectives. 
Table 3: Item-wise Estimated Cronbach's Alpha Test Results.

\begin{tabular}{|c|c|c|c|c|}
\hline $\begin{array}{l}\text { Question } \\
\text { Number }\end{array}$ & $\begin{array}{l}\text { Scale Mean } \\
\text { if Item } \\
\text { Deleted }\end{array}$ & $\begin{array}{l}\text { Scale Variance if } \\
\text { Item Deleted }\end{array}$ & $\begin{array}{l}\text { Corrected Item- } \\
\text { Total Correlation }\end{array}$ & $\begin{array}{c}\text { Cronbach's } \\
\text { Alpha if Item } \\
\text { Deleted }\end{array}$ \\
\hline Q1 & 172.34 & 123.042 & 0.628 & 0.941 \\
\hline Q2 & 172.82 & 125.235 & 0.552 & 0.941 \\
\hline Q3 & 172.97 & 125.972 & 0.747 & 0.941 \\
\hline Q4 & 172.76 & 121.645 & 0.697 & 0.94 \\
\hline Q5 & 172.16 & 122.461 & 0.782 & 0.939 \\
\hline Q6 & 172.5 & 123.23 & 0.597 & 0.941 \\
\hline Q7 & 172.21 & 126.009 & 0.486 & 0.942 \\
\hline Q8 & 172.82 & 124.695 & 0.602 & 0.941 \\
\hline Q9 & 172.16 & 122.191 & 0.807 & 0.939 \\
\hline Q10 & 172.5 & 122.797 & 0.631 & 0.941 \\
\hline Q11 & 172.76 & 128.564 & 0.261 & 0.943 \\
\hline Q12 & 172.61 & 125.218 & 0.502 & 0.942 \\
\hline Q13 & 172.71 & 123.454 & 0.582 & 0.941 \\
\hline Q14 & 173.11 & 128.475 & 0.213 & 0.944 \\
\hline Q15 & 173.39 & 123.543 & 0.444 & 0.943 \\
\hline Q16 & 172.92 & 124.885 & 0.557 & 0.941 \\
\hline Q17 & 172.16 & 122.028 & 0.744 & 0.94 \\
\hline Q18 & 172.42 & 122.737 & 0.637 & 0.94 \\
\hline Q19 & 172.95 & 123.132 & 0.752 & 0.94 \\
\hline Q20 & 172.79 & 122.387 & 0.484 & 0.943 \\
\hline Q21 & 172.5 & 123.176 & 0.601 & 0.941 \\
\hline Q22 & 172.13 & 123.955 & 0.766 & 0.94 \\
\hline Q23 & 172.92 & 128.021 & 0.231 & 0.944 \\
\hline Q24 & 172.53 & 122.094 & 0.687 & 0.94 \\
\hline Q25 & 172.87 & 125.144 & 0.617 & 0.941 \\
\hline Q26 & 172.08 & 122.399 & 0.898 & 0.939 \\
\hline Q27 & 172.18 & 119.722 & 0.844 & 0.938 \\
\hline Q28 & 172.08 & 122.399 & 0.898 & 0.939 \\
\hline Q29 & 172.34 & 125.42 & 0.485 & 0.942 \\
\hline
\end{tabular}

Diagnostic Laboratories - Are These Radiation afe? 


\begin{tabular}{lccccc}
$\begin{array}{l}\text { Rajan, R } \\
\text { Rajkumar, PR }\end{array}$ & $\begin{array}{c}\text { Question } \\
\text { Number }\end{array}$ & $\begin{array}{c}\text { Scale Mean } \\
\text { if Item } \\
\text { Deleted }\end{array}$ & $\begin{array}{c}\text { Scale Variance if } \\
\text { Item Deleted }\end{array}$ & $\begin{array}{c}\text { Corrected Item- } \\
\text { Total Correlation }\end{array}$ & $\begin{array}{c}\text { Cronbach's } \\
\text { Alpha if Item } \\
\text { Deleted }\end{array}$ \\
\cline { 2 - 6 } & Q30 & 173.29 & 126.373 & 0.419 & 0.942 \\
Q31 & 173.05 & 123.186 & 0.238 & 0.952 \\
Q32 & 172.08 & 122.399 & 0.898 & 0.939 \\
Q33 & 172.05 & 124.7 & 0.844 & 0.94 \\
Q34 & 172.08 & 122.399 & 0.898 & 0.939 \\
\hline
\end{tabular}

Table 4: KMO and Bartlett's Test Summary.

\begin{tabular}{lcc}
\hline \multicolumn{3}{c}{ KMO and Bartlett's Test } \\
\hline Kaiser-Meyer-Olkin Measure of Sampling adequacy & $\mathbf{0 . 7 1 8}$ \\
\hline Bartlett's Test of Sphericity & Approx. Chi-Square & 244.296 \\
& df & 21 \\
Sig. & 0 \\
\hline
\end{tabular}

\subsection{Content Validity}

The research questionnaire has been presented to a team of experts comprising Radiation Officers Association, serving as employees and consultants in various hospitals for a detailed review. The initial Questionnaire was designed with 39 questions covering all the seven parameters. It is after a comprehensive discussion and in-depth review by team of experts, the number of questions has been brought down to 34 . The distribution of questions in each parameter has been finalized in accordance with the requirements of study. The expert's team has unanimously agreed that questions were very pertinent to assess compliance to AERB guidelines on the best practices followed by Diagnostic centers taken for this study.

\section{ANALYSIS OF DATA}

The response collected from Diagnostic Centers has been compiled and analyzed using Minitab (Version 15). The overall Radiological Compliance Index (RCI) was estimated as a mean of all the responses from 192 samples. The RCI thus estimated was at 3.18 on a scale of 6 , which means that "Significant Presence" of the best practices recommended by AERB existed in all parameters studied. Similarly, the questions were logically grouped under each parameter and 
responses under each parameter were then tabled to calculate the mean. The estimated mean varied between 2.02 (Top Management Commitment) and 4.04 (Operations Know-How). The distribution of estimated mean on the parameters that constitutes RCI is shown in Fig 3.

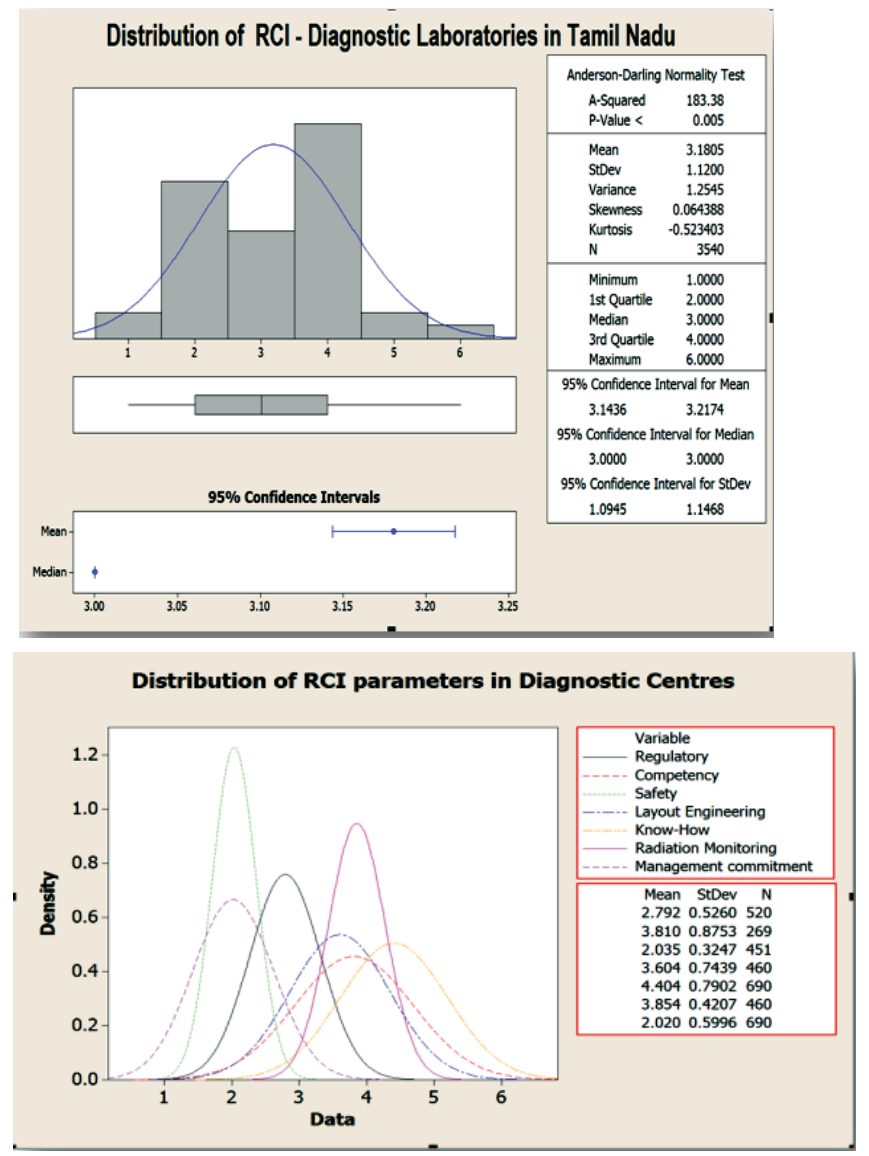

Figure 3: Radiation Containment Parameters Mean Score distribution.

\subsection{Regulatory Requirements}

The diagnostic centers must establish periodical compliance on practices towards buying AERB approved equipments, registration of the facility with AERB online website 'eLORA' (e-Licensing of Radiation Applications), obtaining facility approval and prompt display of facility approval to public in order to meet regulatory related AERB requirements. Those responses pertaining to regulatory parameter were identified and grouped for estimation
Diagnostic Laboratories - Are These Radiation Safe? 
Rajan, R

Rajkumar, PR of mean. The RCI for Regulatory parameter was estimated at 2.79 (fig 4) on a 6 point scale and that reflects compliance to recommended guidelines by AERB on this parameter is close to "Significant Presence".

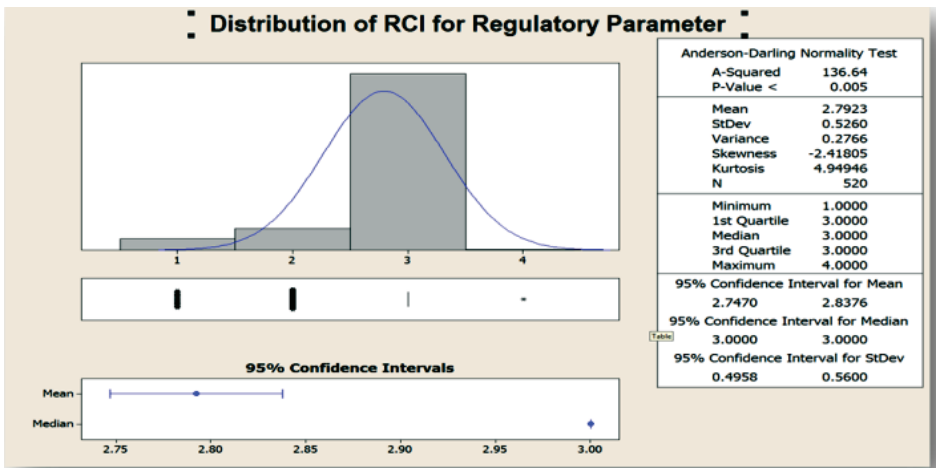

Figure 4: Regulatory Parameter Mean Score.

\subsection{Layout Engineering}

The room layout refers to engineering aspects of the room in which imaging diagnostic equipments will be placed and commissioned, plays a vital role in order to contain the radiation within the perimeter defined and approved by AERB. The key aspects researcher has included in layout compliance assessment covers room dimension, wall thickness, construction material used, Lead (a heavy metal with high density) partition and separating operator's room from equipment room. Any compromise made at this stage in establishing a fully compliant layout for proper placement of the medical device will result in excessive radiation leakage. The responses related to layout engineering compliance from diagnostic laboratories has been identified and analyzed. The actual mean calculated for Layout engineering was at 3.60 (Fig 5), confirmed that the practices are just above" significant levels".

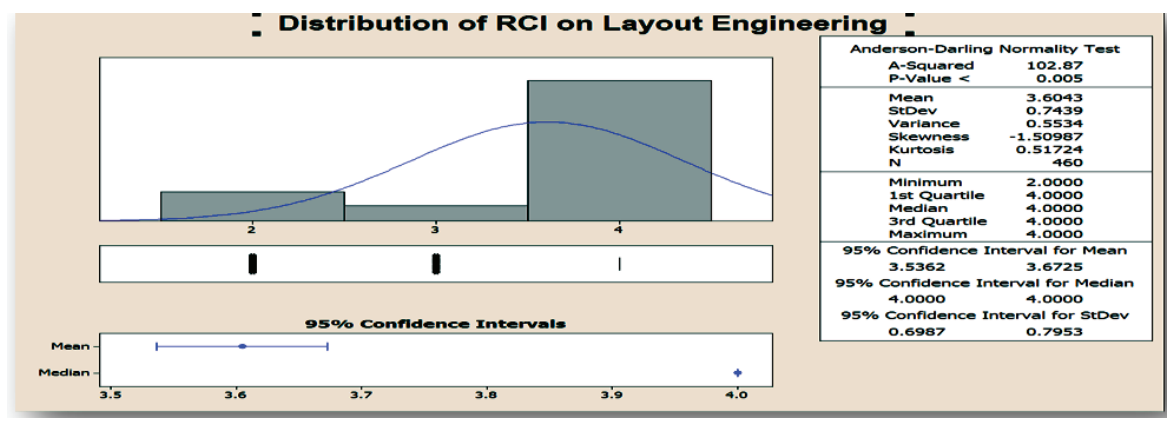

Figure 5: Layout Engineering Parameter Mean Score. 


\subsection{Technicians Competency}

The diagnostic medical imaging devices are high technology driven and integrated with modern computing techniques for enabling full scale automated operation. It is therefore so important to appoint a highly skilled technician who has adequate experience in operating these devices independently. The technician is expected to prepare the key Technical Standards as recommended by the manufacturer and display promptly for reference purposes. This will help the technician to choose the right protocols for exposing patients to radiations during CT/ X-ray scan. The technician must be trained by the software application specialist of the manufacturer to acquire competency on handling and managing the software. The mean computed was at 3.81(Fig 6) on technician competency related regulatory requirements and that reaches close to "High Presence" of best practices recommended by AERB. Lee et al., (2004) has conducted an assessment on the awareness of radiation dose and possible risks among patient, physician and radiologist.

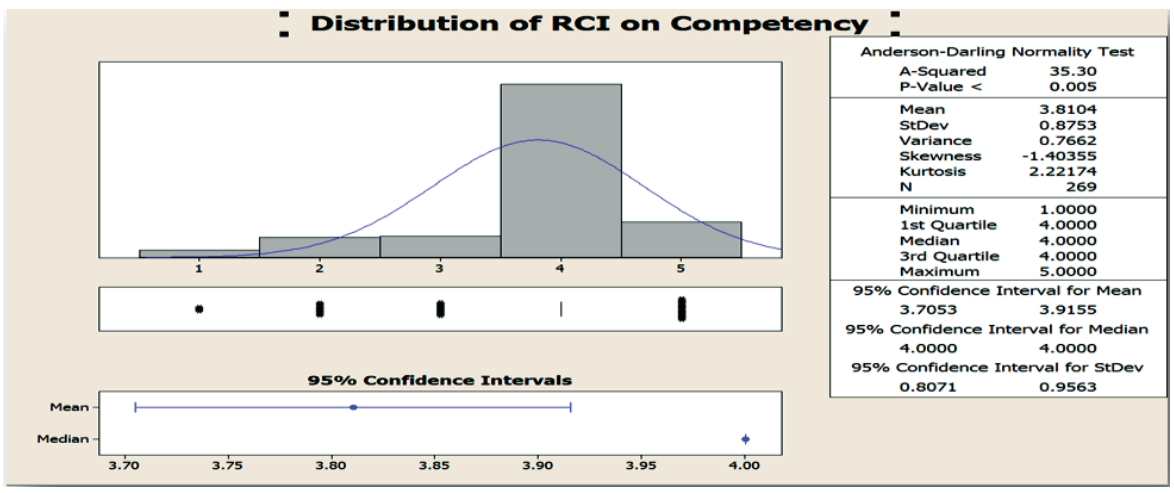

Figure 6: Technician Competency Parameter Mean Score.

\subsection{Human Safety}

It is to be noted that everyone inside the X-ray room is exposed to radiation, when a patient undergoes scan including the technician, who operates the equipment and manages the patient until the scan is fully completed. Hence protecting people from excessive radiation must be the top most priority for the regulator and the Diagnostic Centers management. AERB has stipulated threshold limit for radiation exposure, methods for measuring and taking corrective measures on a regular basis. The radiation exposure limit is defined as an effective dose of $20 \mathrm{mSv} / \mathrm{year}$ averaged over five consecutive years (calculated on a sliding scale of five years). The radiation exposure unit is defined in millisievert, denoted
Diagnostic

Laboratories - Are

These Radiation

Safe?

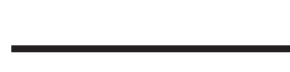


Rajan, R

Rajkumar, PR as mSv. The technician must wear a TLD (Thermo Luminescent Dosimeter) at the chest level during patient scan, which measures ionizing radiation exposure by measuring the intensity of visible light emitted from a crystal in the detector when the crystal is heated. This TLD badge is sent on a quarterly basis to AERB approved laboratories wherein the radiation exposure actual dosages is estimated and reported to the employer. The Technician shall use LEAD APRONS to protect from excessive radiation during patient scan using mobile X-ray devices, for bedside patients who are immobile. The X-ray room must be installed with a LEAD door so as to absorb the radiation emanated from the $\mathrm{X}$-ray tube. The equipment must be certified by conducting QA (Quality Assurance) test for its effective functioning and fitness is reassured at least every year by the AERB recommended third party testing agencies. The World Health Organization has published a report on Quality Assurance in Diagnostic Radiology in 1982, which can be used as a reference standard by the Diagnostic Laboratories and manufacturers. The mean calculated to assess compliance on all the above human safety related best practices was at 2.04 (Fig 7), which does not augur well for such an important compliance requirements. Hence, the human safety related compliance best practices assessed indicates at "Moderate Presence".

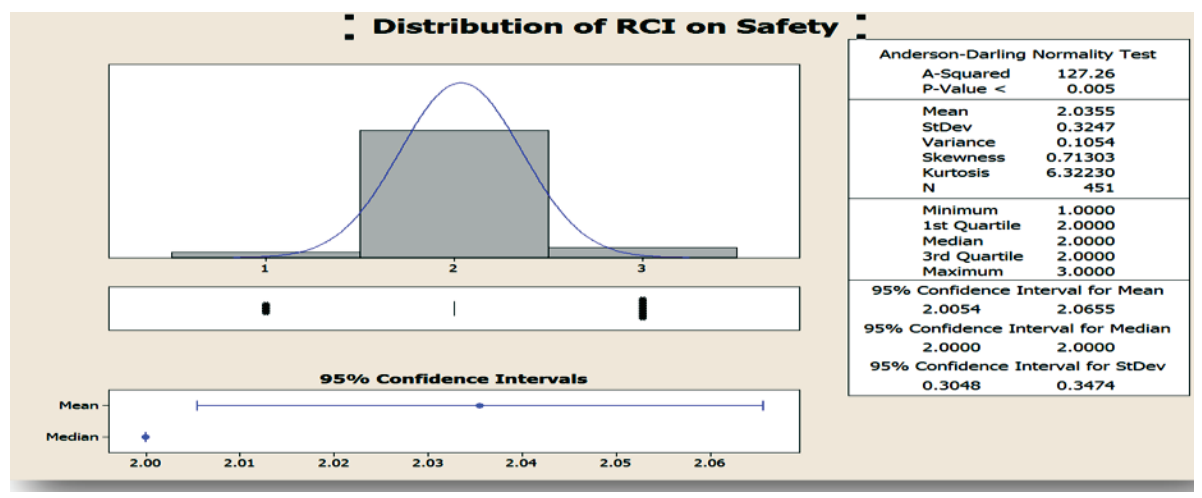

Figure 7: Human Safety Parameter Mean Score.

\subsection{Operations "Know-How"}

The technician knowledge and skills are important in managing the equipment for extended usage and achieving optimal radiation exposure levels as per the norms. The collimeter, a device that narrows a beam of particles or waves, attached to the X-ray machine needs to be manipulated rightly for emanating the specified X-Ray beams and aligning their path ways. The technician must be highly skilled in handling the collimeter during the patient scan for maneuvering intensity and direction of the light. White (1996) has conducted 
a research on usage of CT in pediatric medicines. Paterson et al., (2001) has studied settings to be adjusted while using Helical CT on pediatric patients. The X-Ray room tends to become extremely hot due to the continuous heating of X-ray tube and radiation exposure. So the temperature inside the room must be monitored and maintained as per the recommendations of the manufacturer for optimal utilization of X-ray tube until the specified life time. The TLD badge must be used at the chest level during the scan and retained in a safe place outside the X-ray room when not in use. The technician must ensure that abdomen is fully covered by lead apron when performing scan for pregnant women. The pediatric protocols must be used as recommended by the manufacturer when children under go scan. The radiation stickers and signage must be displayed at appropriate locations as a preventive measure. The responses received from diagnostic laboratories on the above lines have been analyzed and the mean computed. This has shown a mean of 4.40 (Fig 8), which reflects that practices pertaining to operations 'Know-How" is just above "High Presence".

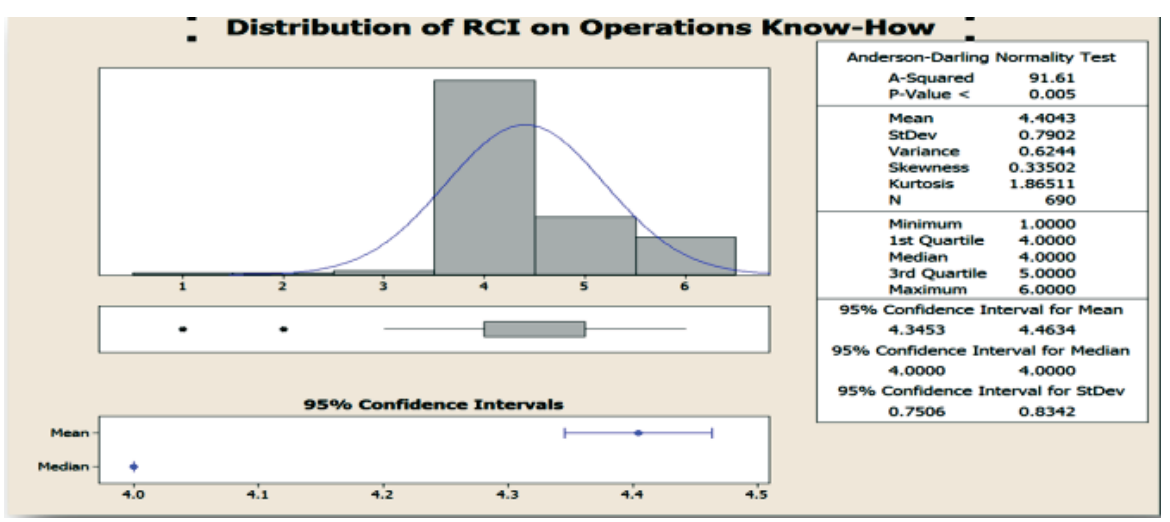

Figure 8: Operations Know-How Parameter Mean Score.

\subsection{Monitoring Radiation Exposure}

Wall \& Hart (1997) has recommended a revised radiation doses based on the extensive dosage study with 5000 patients. Groves et al., (2004) have emphasized the need of scientific estimation of radiation dosed in their research using 16 Detector multislices CT with Monte Carlo Simulation. The technician who performs the scan is continuously exposed for radiation and the risk of excessive radiation exposure beyond the threshold limits set by AERB is very high. Hence the technician must ensure that the TLD badge is used always during scan. This TLD badge is collected on a quarterly basis and sent to AERB authorized laboratory for estimation of the actual radiation dose.
Diagnostic Laboratories - Are These Radiation Safe? 
Rajan, R

Rajkumar, PR

The diagnostic center management must constantly review the cumulative radiation and incase of any aberration against the specification, the technician must be relieved from the duty and sent on a paid leave for at least 3 months. An incident report is logged and the technician radiation dose is monitored until return to normalcy. The Equipment is also tested and qualified by a third party authorized QA test agency annually for its fitness. These practices will ensure that AERB guidelines are followed towards achieving high compliance in monitoring radiation exposure activities. The mean calculated for this practice compliance has shown a value of 3.65 (Fig 9), which represents practices that exists slightly above 'Significance Level'.

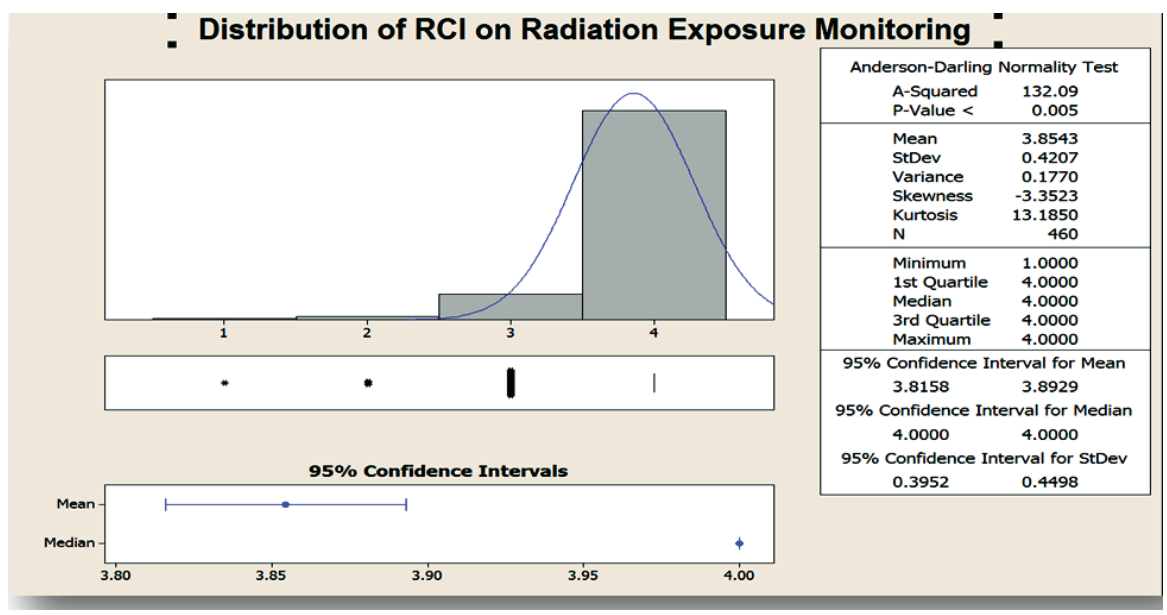

Figure 9: Radiation Exposure Parameter Mean Score.

\subsection{Top Management Commitment}

The Top Management commitment is absolutely essential in establishing and maintaining best practices against the standards recommended by AERB. The equipment buying decision, ensuring fitness certification of the equipment before commencing commercial scan, complying with AERB approved equipment purchase, adequate allocation of funds for buying apron, appointment of full time Radiation Safety Officer, periodical training of technician and investment in periodical equipment maintenance by the manufacturer or qualified third party service providers are the prime responsibilities of Top Management. The Top Management commitment, based on the responses collected on the above parameters was estimated with a mean value of 2.02. This has revealed that the Top Management commitment in establishing best practices was at a "moderate level", as shown in fig10. 


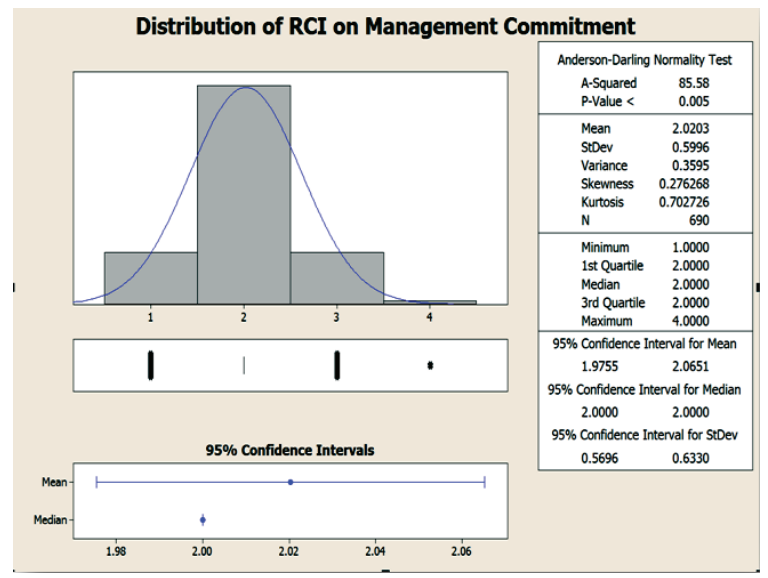

Diagnostic

Laboratories - Are

These Radiation

Safe?

Figure 10: Top Management Commitment Parameter Mean Score.

\subsection{Relationship between Revenue and Radiation Compliance Index}

The researcher has formulated a hypothesis to test the relationship between Revenue and Radiation Compliance Index. The implementation of regulatory guidelines must be supported with adequate fund by the Top Management at appropriate stages in order to establish sustainability. However, the allocations of funds depend largely on the revenue and so Pearson correlation co-efficient was tested to understand the relationship. The Pearson correlation coefficient has been computed with an " $r$ " value of +0.312 and " $p$ " value of 0.001 (fig 11 ). This shows a moderate positive correlation between revenue and Radiation Compliance Index.

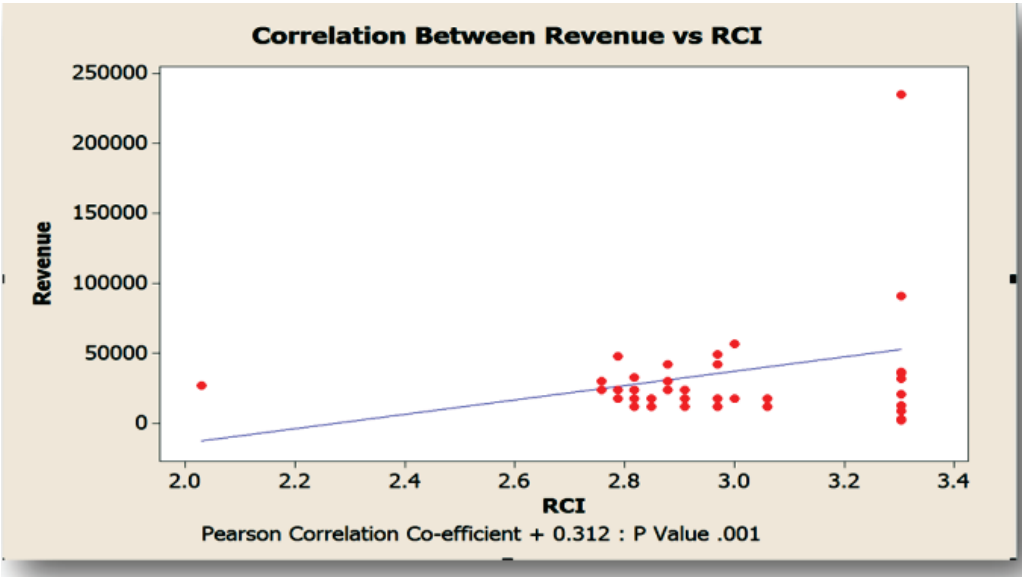

Figure 11: Relationship between Revenue and Radiation Compliance Index. 
Rajan, R

Rajkumar, PR

\subsection{Relationship between Patient Queue Size and Radiation Compliance Index}

The researcher has assumed that an increase in patient flow will have positive impact on Radiation compliance index and accordingly formulated a hypothesis. This assumption was made to test whether increase in patient inflow will create a positive pressure on Top Management for paying high attention in improving the regulatory compliance. The Pearson correlation coefficient estimated was +0.293 with a " $p$ " value of 0.001 . This establishes a low positive correlation between the patient queue size and compliance index as shown in fig 12 .

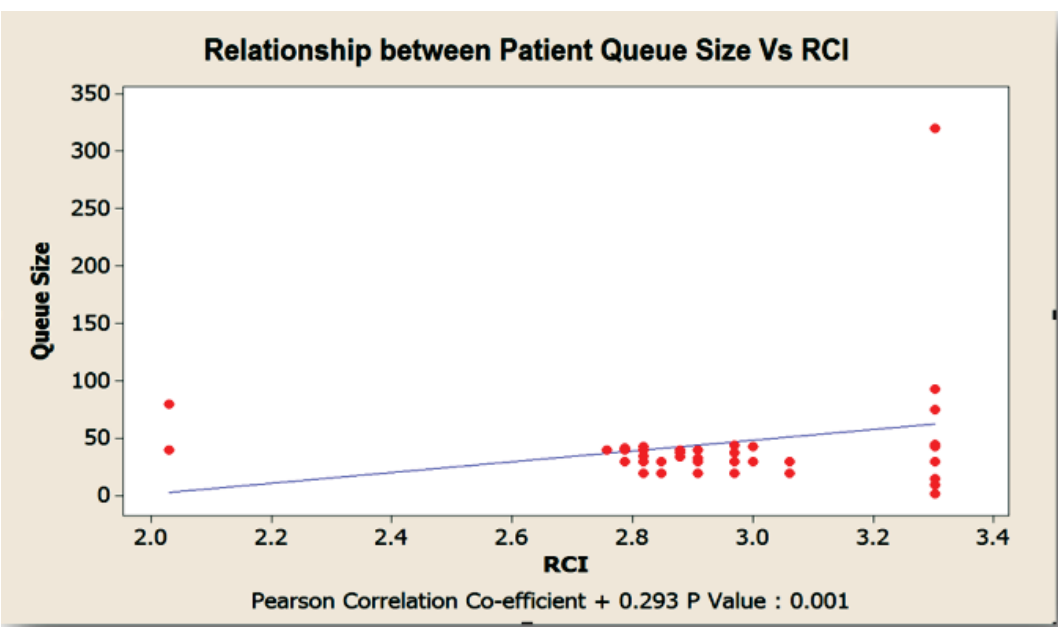

Figure 12: Relationship between Patient Queue Size and Radiation Compliance Score.

\subsection{Relationship between NABL and Non-NABL accredited Diagnostic Laboratories}

The Diagnostic Centers accreditation against NABL is based on ISO / IEC 17025 standards, which has been designed to focus on quality of testing and calibration of the instruments used for initial diagnostic purposes. The implementation of NBAL will bring in system discipline across the functions which could facilitate augmenting with AERB system requirements. The mean score of all the parameters studied is tabulated in table 5 .

The researcher has used one way ANOVA for analysis at 95 percent confidence interval, to test whether any significant differences exist between the means of NABL and Non-NABL diagnostic centers compliance score. The ANOVA results have shown a very low 'F" Value (0.0046) and 'p' value (0.9982) which is greater than the alpha (0.05) at 95 percent confidence 
interval. These results have failed to accept Null Hypothesis. This result has suggested that there were not enough evidences to support the argument that NABL certification will influence Radiological Compliance Score. The ANOVA results are shown in table 6.

Table 5 : Mean Score on Radiation Compliance for NABL and Non-NABL Diagnostic centers.

\begin{tabular}{cccccccc}
\hline $\begin{array}{c}\text { Category } \\
\text { of }\end{array}$ & $\begin{array}{c}\text { Mean } \\
\text { Score on }\end{array}$ & $\begin{array}{c}\text { Mean } \\
\text { Score } \\
\text { on } \\
\text { Institution }\end{array}$ & $\begin{array}{c}\text { Regulatory } \\
\text { Score on } \\
\text { Layout }\end{array}$ & $\begin{array}{c}\text { Mean } \\
\text { Score } \\
\text { on }\end{array}$ & $\begin{array}{c}\text { Mean } \\
\text { Score on } \\
\text { Know- }\end{array}$ & $\begin{array}{c}\text { Mean } \\
\text { Score on } \\
\text { Safety } \\
\text { Rowiation } \\
\text { Monitoring }\end{array}$ & $\begin{array}{c}\text { Mean Score } \\
\text { on Top } \\
\text { Management } \\
\text { Commitment }\end{array}$ \\
\hline NABL & 2.768 & 3.771 & 3.871 & 2.137 & 4.374 & 3.795 & 2.091 \\
Non- & 2.697 & 3.567 & 3.951 & 2.058 & 4.439 & 3.853 & 2.003 \\
NABL & & & & & & & \\
\hline
\end{tabular}

Table 6 : ANOVA Results for NABL and Non-NABL Diagnostic Centers.

\begin{tabular}{cccccc}
\hline Source & df & SS & MS & F & P - Value \\
\hline Treatment & 1 & 0.004 & 0.004 & & \\
error & 12 & 10.678 & 0.890 & 0.0046 & 0.9982 \\
Total & 13 & 10.682 & & & \\
\hline
\end{tabular}

\section{INTERPRETATIONS AND RECOMMENDATIONS}

The detailed data analysis on compliance to regulatory guidelines to assess the existing 'as-is' practices followed by Diagnostic Centers towards protection of employees and patients from excessive radiation has shown an overall mean 3.18, which indicates that the recommended practices by the regulator are "Significantly Present". The mean score for all the seven parameters that constitutes the overall Radiation Compliance Index is shown in the table 7.

From the table 7, it was quite evident that the "Top Management commitment (2.02)", Human Safety (2.04) and Regulatory (2.76) related practices were found to be present only at a 'Moderate Level'. An in-depth review of question wise responses for Top Management commitment has revealed that allocation of funds for equipment periodical maintenance services (1.97), appointment of full time radiation safety officer (2.0), Making sufficient number of Aprons available for use, Technicians' skill enhancement training fund (2.39) and Apron testing at third party lab (1.20) have contributed for low compliance score. Hence, it is to be noted that Top Management has failed to fulfill its responsibilities towards achieving high compliance score.
Laboratories - Are

These Radiation

Safe? 


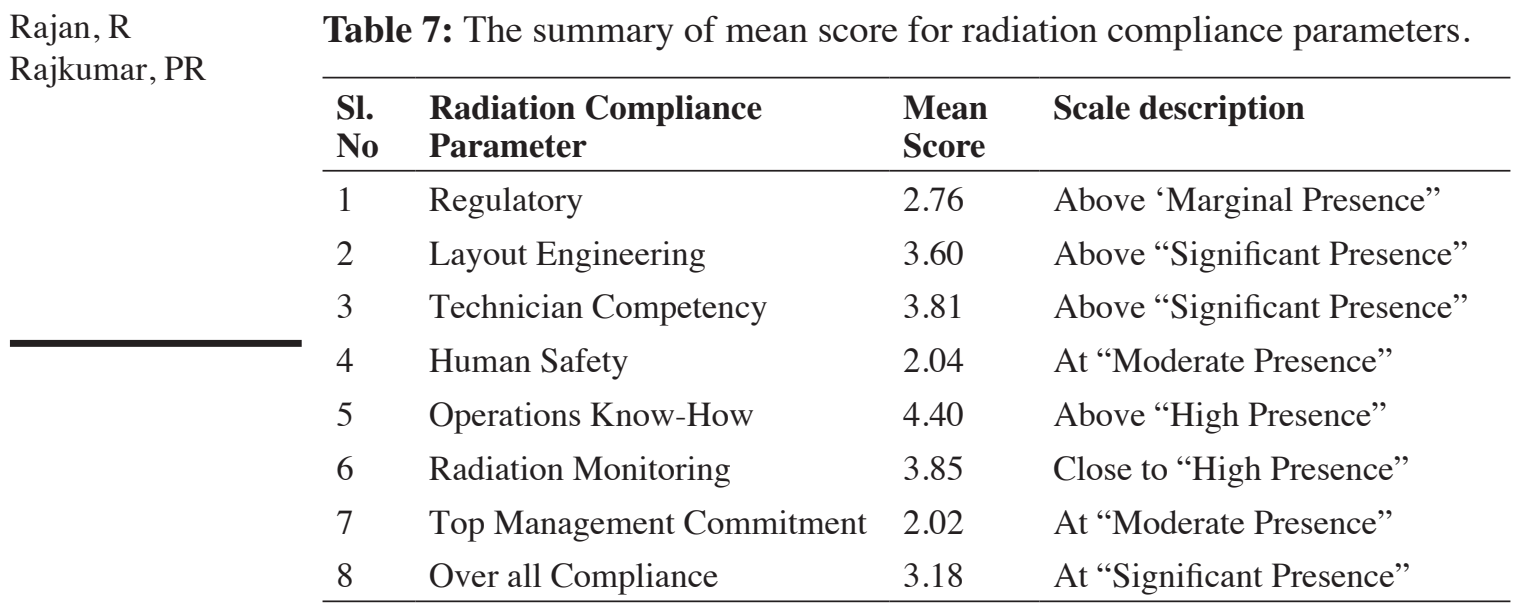

The compliance score for "Human Safety" has been estimated with a mean value of 2.04 which reflects the practices to contain radiation safety existed at "Moderate" level. The low score was attributed to inadequate compliance on some of the key requirements such as, wearing TLD badge at chest level during patient scan (2.01), proactive x-ray room lead door closure (2.42) and Lead apron usage during mobile $\mathrm{x}$-ray unit scan (1.80) at the bedside.

The compliance score on mandatory "Regulatory requirements" prior to initiating the diagnostic imaging equipments buying was calculated as 2.76 which enunciate that the practices followed to comply with AERB recommendations are found to be just above "Marginal Presence". The researcher detailed analysis of responses have identified three main reasons as the root cause such as, poor awareness at the management level on usage of AERB online portal "eLORA" for accessing list of equipments for which type approval has been accorded (2.05), continuous updation of changes in employees profile in the online portal (1.52) and prompt display of facility approval for public access (3.30).

The compliance score on "layout engineering" has been estimated as 3.60, which demonstrates that efforts made by the technician and operations team to put the best practices on a day-to-day basis for compliance to equipment room layout are found to be above "Significant' level. However, changes to equipment room layout (2.02), monitoring the usability of lead door (2.16) and carrying out repair work under controlled conditions (2.24) are the activities that led to low compliance.

The compliance score on "Technician competency" was 3.81 , found to be better than the parameters discussed above revealed that the process practices followed in successfully managing the equipment for its better usability and 
extended life were identified just above "Significant Presence" level. The appointment of qualified technician by the management (1.98) and continuous training for upgradation of skills by the manufacturer's application specialist (2.68) are the areas in which the compliance score were found to be low.

The "Monitoring of Exposure to Radiation" is the true reflection of effective radiation exposure undergone by the technician in dosage limits is estimated at 3.85, which illustrates that the practices existed close to "High Presence" level. The non-submission of TLD badges on a quarterly basis with AERB approved test centers for estimation of radiation dosage levels (2.01), reviewing test reports on the actual radiation dosage for further declaration of an incident (2.12) and carrying out Quality Assurance test for certification of equipment fitness every 2 years (2.02) are the process practices that were not fully present.

The "Operations Know-How" is a parameter that reflects how well the diagnostic equipment is operated and the complete environment in which the equipment housed is maintained. The compliance score on operations know-how was estimated at 4.40 (above High Level presence), which is the highest score when compared to all the other six compliance parameters. The review of responses to various questions under this category has identified process practices related to usage of collimeter for right sizing of radiation exposure (4.8), meticulous identification of radiation zone using radiation stickers \& signage's (5.2) and application of pediatric protocols when children scan is performed (5.4) are the high compliance areas. The activities in which further improvements in establishing higher score are extracted from the responses which covers monitoring the temperature and humidity inside $\mathrm{x}$-ray room (2.20), storage of TLD badges outside the x-ray room when not in use (3.40) and masking abdomen with Lead apron when pregnant women scan is performed (2.88).

The Pearson correlation coefficient (' $r$ ' +0.312 with a 'p' value 0.001 ) has failed to establish a strong positive relationship between Revenue and Radiation Compliance Index. The analysis results have indicated that these two variables have moderately positive relationship. It is expected that the Top Management must allocate adequate fund for establishing higher regulatory compliance with higher revenue. Similarly, the relationship between patient queue size and Radiation Compliance Index was found to be weak, though the calculated Pearson correlation co-efficient ' $r$ ' is +0.293 with a ' $p$ ' value of 0.001 . This result has failed to justify the assumption that higher patient queue size will create adequate pressure on Top Management to achieve high Radiation Compliance Index. NABL certification did not have any impact on radiation compliance Index, which suggests that the evaluation criteria for
Diagnostic

Laboratories - Are

These Radiation

Safe?

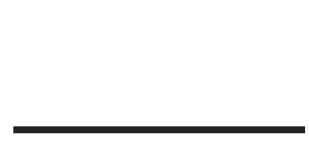


Rajan, R

Rajkumar, PR assessment of practices before issuing the certification do not include AERB guidelines on radiation safety controls.

The first step in change implementation is to appoint a competent Leader who can spear head the entire Change Management Program. Hence, it is essential to recognize implementation of AERB regulatory requirements as a change program and the Top Management must appoint Radiation Safety Officer as a full time resource for this change initiative. The regulator, AERB must design and deliver specific training programs only for the owners of Private Diagnostic Centers in order to make them aware of the risks of non compliant with the regulatory guidelines. This program must certify the attendees that they have understood the role of Top Management and learnt the mitigation plans for successful implementation of the regulator guidelines.

This research work has been confined only with the samples drawn from within Tamil Nadu and it is recommended that similar research studies can be conducted across different states in India covering more Private Diagnostic Centers. This will help in understanding the current actual status of business process maturity levels towards implementation of regulator guidelines. A research work on "Comparative analysis of implementing Regulator guidelines in containment of radiation between Government Hospitals and Private Diagnostic Centers" can be initiated to identify the status of Government Hospitals in implementation of relevant systems, which caters its services to a large amount of general public. It is also proposed to undertake a research wok on "A framework for successful implementation of Regulatory guidelines for Radiation Protection", which can help the Diagnostic centers and Hospitals housing Diagnostic Imaging Equipments, for performing self assessment and continual improvement.

\section{CONCLUSION}

It was quite evident from this research study that private diagnostic centers housing diagnostic imaging equipments in Tamil Nadu have adequately protected the $\mathrm{x}$-ray emanating equipments from any plausible excessive radiation through a robust layout engineering, operations know-how and radiation monitoring controls. The regulator (AERB) has orchestrated the dissemination of equipment layout requirements very meticulously through the Manufacturer submitting the layout for a formal review and approval by AERB while commissioning of the equipment. This is an important control for ensuring that no excessive radiation leakage is permitted to the human as well as to the surrounding external environment. However, the process practices followed by the diagnostic centers towards holistic deployment of all aspects of AERB guidelines are not adequate and extensive Top Management 
involvement in this change program is not visibly seen. On a top priority, Diagnostic Centers need to put in place some of the key controls such as appointment of Radiation Safety Officer, encouraging the maximum use of AERB portal (eLORA), continuous training of their staff and technicians, monitoring the radiation exposure dosage and corrective measures and uncompromised equipment service contracts, in order to achieve the overall objective set forth by the regulator. Hence further research on comparative study of practices followed by the institutions such as Corporate Hospitals, Government Hospitals, Chain of Diagnostic Centers and Private Diagnostic Centers can be a greatest socio-economic contribution which can instill high confidence to the public that they are radiation safe when undergoing for a scan. A research on "Diagnostic Imaging Equipments Regulatory Framework for Evaluation of Business Practices" can help the implementers towards shifting their focus for achieving highly matured business practices.

\section{REFERENCES}

[1] Beinfeld, M.T., Wittenberg. E, \& Gazelle, G. S. (2005). Cost-effectiveness of whole-body CT screening. Radiology, 234, 415-422.

[2] Brenner, D.J, Doll, R, \& Goodhead, D.T, et. al., (2003). Cancer risks attributable to low doses of ionizing radiation: assessing what we really know. Proc Natl Acad Sci, U.S.A, 100, 13761-13766.

[3] Berrington de Gonzalez, A., \& Darby, S. (2004). Risk of cancer from diagnostic X-rays: estimates for the UK and 14 other countries. Lancet, 363, 345-351.

[4] Brenner, D.J, \& Elliston, C.D. (2004). Estimated radiation risks potentially associated with full-body CT screening. Radiology, 232, 735-738.

[5] Brenner, D.J. (2004). Radiation risks potentially associated with low-dose CT screening of adult smokers for lung cancer. Radiology, 231, 440-445.

[6] Brenner, D.J, \& Georgsson, M.A. (2005). Mass screening with CT colonography: should the radiation exposure be of concern?. Gastroenterology, 129, 328-337.

[6] Brenner, D.J. (2006).It is time to retire the computed tomography dose index (CTDI) for CT quality assurance and dose optimization. Med Phys, 33, 1189-1191.

[7] Brenner, D.J, \& Hall, J. (2007).Current concepts: Computed Tomography - An increasing source of radiation exposure, N.Enj. Med, 357, 2274-2284.

[8] Cronbach, L. J. (1951). Coefficient alpha and the internal structure of tests. Psychometrika, 16, 297-334.

[9] Djermouni, B, \& Boal.T (2007). International Atomic Energy Agency, Regulatory Control of Radiation Sources, IAEA Safety Standards Series No. GS-G-1.5, IAEA, Vienna.
Diagnostic

Laboratories - Are

These Radiation

Safe? 
Rajan, R

Rajkumar, PR

[10] Fenghueih, H.(1998). Integrating ISO 9001:2000 with TQM spirits. A survey on Industrial Management Data Systems. 8, 373-379.

[11] Giles, J. (2004). Study warns of 'avoidable' risks of CT scans. Nature, 431-391.

[12] Groves, A.M, Owen, K.E, \& Courtney, H.M, et al.(2004) 16-Detector multislice CT: dosimetry estimation by TLD measurement compared with Monte Carlo simulation. Br J Radiol, 77, 662-675.

[13] Lee, C.I, Haims, A.H, Monico, E.P, Brink, J.A, \& Forman, H.P. (2004). Diagnostic CT scans: assessment of patient, physician, and radiologist awareness of radiation dose and possible risks. Radiology, 231, 393-398.

[14] Linton, O.W, Mettler, F.A. Jr. (2003) National conference on dose reduction in CT, with an emphasis on pediatric patients. AJR Am J Roentgenol, 181, 321-329.

[15] Martin, C.J, Sutton, D.G, \& Sharp, P.F.(1999). Balancing patient dose and image quality. Appl Radiat Isot, 50, 1-19.

[16] McNitt-Gray, M.F. (2002). AAPM/RSNA physics tutorial for residents - topics in CT: radiation dose in CT. Radiographics, 22, 1541-1553.

[17] Mettler, F.A. Jr, Wiest, P.W, Locken, J.A, \& Kelsey, C.A. (2000). CT scanning: patterns of use and dose. J Radiol Prot, 20, 353-359.

[18] Oikarinen, H., et al., (2009). Unjustified CT examinations in young patients, Eur. Radiol, 195, 1161-1165.

[19] Ortiz Lopez, P. (2006). International Atomic Energy Agency, Applying Radiation Safety Standards in Nuclear Medicine, Safety Reports Series No. 40, Printed by IAEA, Austria.

[20] Ortiz Lopez, P. (2006). International Atomic Energy Agency, Applying Radiation Safety Standards in Radiotherapy, Safety Reports Series No. 38, Printed by IAEA, Austria.

[21] Ortiz Lopez, P. (1999). International Atomic Energy Agency, Organization and Implementation of a National Regulatory Infrastructure Governing Protection Against Ionizing Radiation and the Safety of Radiation Sources: Interim Report for Comment, IAEA-TECDOC-1067, IAEA, Vienna.

[22] Paterson, A, Frush, D.P, \& Donnelly, L.F. (2001). Helical CT of the body: are settings adjusted for pediatric patients? AJR Am J Roentgenol, 176, 297-301.

[23] Richard, I.L. \& Davis, S.R. (2001). Statistics for Management, 7th Edition, Prentice-Hall: 791-795.

[24] Richard Monson, R., James Cleaver, E., Herbert Abrams, L., et al. (2006). Health risks from exposure to low levels of ionizing radiation - BEIR VII. Washington, DC: National Academies Press, Washington D.C.

[25] Sources and effects of ionizing radiation: United Nations Scientific Committee on the Effects of Atomic Radiation: UNSCEAR 2000 report to the General Assembly. New York: United Nations, 2000. 
[26] United Nations Scientific Committee on the Effects of Atomic Radiation. Sources and effects of Ionizing radiation, Vol. 1: Sources. New York, NY: United Nations Publishing; 2000.

[27] Wall, B.F, \& Hart, D. (1997). Revised radiation doses for typical x-ray examinations. (5,000 patient dose measurements from 375 hospitals). The British Journal of Radiology, 70, 437-439.

[28] What's NEXT? Nationwide Evaluation of X-ray Trends: 2000 computed tomography.(CRCPD publication no. N EXT_2000CTT.) Conference of Radiation Control Program Directors, Department of Health and Human Services, 2006.

[29] White, K.S. (1996). Helical/spiral CT scanning: a pediatric radiology perspective. Pediatr Radiol, 26, 5-14.

[30] World Health Organization, (1982). Quality Assurance in Diagnostic Radiology, WHO, Geneva.
Diagnostic

Laboratories - Are These Radiation

Safe? 